
jul-set 2005 .

\title{
Rendimento e qualidade do melão sob lâminas de irrigação e cobertura do solo com filmes de polietileno de diferentes cores
}

\author{
Maria Zuleide de Negreiros ${ }^{1}$; Francisco de A. Costa ${ }^{1}$; José Francismar de Medeiros ${ }^{1}$; Mário de M.V.B.R. \\ Leitão $^{2}$; Francisco Bezerra Neto ${ }^{1}$; José Espínola Sobrinho ${ }^{1}$ \\ ${ }^{1}$ ESAM, C. Postal 137, 59625-900 Mossoró-RN; E-mail: zuleide@esam.br; 2UNIVASF, 56306-410 Petrolina-PE.
}

\section{RESUMO}

O experimento foi conduzido de abril a julho de 2002, na Fazenda Santa Júlia Agro-Comercial Exportadora de Frutos Tropicais Ltda, Mossoró, para avaliar o efeito da cobertura do solo com filmes de polietileno de diferentes cores (amarelo, marrom, preto, prateado e solo descoberto) e lâminas de irrigação (100, 86 e $71 \%$ da lâmina padrão) sobre o rendimento e qualidade do melão 'Gold Mine' cultivado na época chuvosa. $\mathrm{O}$ delineamento experimental utilizado foi o de blocos completos casualizados em esquema fatorial $5 \times 3$, com quatro repetições. Foram avaliados o número e produtividade de frutos comerciáveis, refugos e totais, massa média de frutos comercializáveis, classificação dos frutos, firmeza da polpa, espessura da polpa e teor de sólidos solúveis. Houve interação significativa entre os tipos de coberturas de solo e lâminas de irrigação para a massa média de frutos comercializáveis, com os filmes de polietileno registrando os maiores valores em relação ao solo descoberto. Os maiores rendimentos de frutos comercializáveis e totais, percentagens de frutos tipo exportação, teores de sólidos solúveis e espessura de polpa foram obtidos nas coberturas com filmes de polietileno. As lâminas de irrigação não afetaram de modo significativo a produção e qualidade dos frutos.

Palavras-chave: Cucumis melo, filmes de polietileno, manejo de irrigação, produtividade, sólidos solúveis totais.

\section{ABSTRACT}

Yield and fruit quality of melon cultivated under irrigation depths and coverage with polyethylene film of different colors

The experiment was carried out during the period of April to July 2002 in the field, in Mossoró, Rio Grande do Norte State, Brazil, to evaluate the effect of soil coverages with polyethylene films of different colors (yellow, brown, black, silvered and no soil coverage) and irrigation depths $(100 \%, 86 \%$ and $71 \%$ of standard depth) on fruit quality and yield of Gold Mine melon cultivated during rainfall season. The experiment was arranged in a $5 \times 3$ factorial, in randomized complete blocks design, with four replications. We evaluated the number and yield of commercial fruits, non-commercial and total fruits,fruit mean mass, fruit classification, pulp firmness and thickness, and total soluble solids content. There was significant interaction between coverage types and irrigation depths for mean mass of commercial fruits, with the polyethylene films registering greater values compared to the control treatment. Highest commercial and total fruit yield and percentage of export type fruits, total soluble solids content and pulp thickness were obtained using polyethylene films. The irrigation depths did not influence yield and quality of fruits.

Keywords: Cucumis melo, polyethylene films, water management, yield, total soluble solids.

(Recebido para publicação em 21 de julho de 2004 e aceito em 8 de junho de 2005)

$\mathrm{O}$ melão é cultivado nos polos agrícolas Mossoró-Assu (RN) e Baixo Jaguaribe (CE) de julho a dezembro quando as condições edafoclimáticas, principalmente a ausência de chuvas, favorecem o crescimento e desenvolvimento da cultura. O plantio no período das chuvas tem sido um dos grandes desafios para os produtores da região, devido aos problemas fitossanitários. As pragas e doenças prejudicam sensivelmente a cultura, forçando a suspensão das atividades durante praticamente um semestre inteiro, comprometendo o rendimento e a qualidade dos frutos.

Uma alternativa para minimizar as condições desfavoráveis ao plantio e obter melhores preços na entressafra do melão, é o uso da cobertura dos solos com filmes de polietileno, que têm apresentado resultados positivos em relação à produtividade das culturas (SGANZERLA, 1991; SAMPAIO; ARAÚJO, 2001). A cobertura do solo com plástico além de possibilitar redução das perdas de água por evaporação, regular a temperatura do solo, reduzir as perdas de nutrientes por lixiviação, controlar as doenças e ervas daninhas, melhorar a eficiência do uso da água e absorção de fertilizantes (BAKER et al., 1998), evita também que os frutos fiquem em contato direto com o solo, influindo na sua qualidade e aparência, o que permite uma comercialização mais lucrativa.

Vários tipos de filmes plásticos podem ser empregados para cobertura dos solos: opacos, pretos, transparentes, brancos, marrons, cinza, amarelos e prateados. Dependendo da coloração, opacidade ou transparência, os mesmos apresentam maior ou menor capacida- de de transmitir radiações caloríficas e visíveis onde a escolha da cor vai depender das condições climáticas (SGANZERLA, 1991; SAMPAIO; ARAÚJO, 2001).

Os filmes brancos e aluminizados apresentam maior capacidade de reflexão da luz solar e os pretos proporcionam maior capacidade de transmissão que o filme aluminizado (HAM et al., 1993). Os filmes transparentes têm capacidade de transmitir aos solos elevado percentual de radiações solares, ocasionando aumento da temperatura e conseqüentemente elevação da evaporação, formando um filme d'água no plástico, que dificulta a perda de calor durante a noite (SAMPAIO; ARAÚJO, 2001). Por esse motivo, na região Nordeste, os filmes plásticos transparentes são usados para solarização. 
A maior parte dos raios solares é refletida, quando o solo está coberto com filmes plásticos prateados, transmitindo pouca energia aos solos, evitando o aquecimento, sendo um dos materiais sintéticos mais adequados para regiões quentes (SGANZERLA, 1991). Araújo et al. (2000) observaram que o filme prateado promoveu menor aquecimento do solo a $5 \mathrm{~cm}$ de profundidade do que o filme preto ou o solo descoberto.

Streck et al. (1997) observaram que os filmes plásticos brancos, amarelos e verdes apresentaram maior refletividade à luz solar, e que, no período diurno, a temperatura do solo foi maior sob filmes pretos, azuis e vermelhos.

Algumas vantagens atribuídas ao uso da cobertura do solo com plástico, observadas em trabalhos com melão na região, no período de estiagem estão relacionadas com o desenvolvimento vegetativo em melão Amarelo e Cantaloupe (SILVA, 2002; PÔRTO et al., 2003), número total de frutos, número de frutos comercializáveis, massa média de frutos, rendimento total e comercilizável, e teor de sólidos solúveis totais em melão Amarelo e Cantaloupe (SILVA, 2002; ALMEIDA NETO, et al., 2003; SALDANHA et al., 2003), rendimento de frutos comercializáveis (FERREIRA et al., 2001) e firmeza de polpa em melão Amarelo (ARAÚJO et al., 2000).

Embora trabalhos tenham constatado que a cobertura plástica do solo é uma prática viável e importante para a região sobre vários aspectos, deve-se ter cuidado no manejo da água. Não deve ser aplicada a mesma lâmina utilizada para solo sem cobertura pois pode ser elevada e assim favorecer o aparecimento de doenças e reduzir a qualidade dos frutos (ALVES, 2000). Por outro lado, a aplicação de uma lâmina inferior à exigida pela cultura pode influenciar também a qualidade dos frutos (MEDEIROS et al., 2000).

O manejo da irrigação é, pois, o fator indispensável para o sucesso na produção de melão, tanto no que se refere à produtividade como à qualidade dos frutos. A temperatura, umidade relativa, insolação e velocidade do vento são alguns parâmetros climáticos, que ao lado do estádio fenológico da cultura, textu- ra e cobertura do solo, definem a necessidade de água para a cultura (COSTA et al., 2000)

Neste trabalho avaliou-se os efeitos da cobertura do solo com filmes de polietileno de diferentes cores e lâminas de irrigação no rendimento e qualidade do melão 'Gold Mine' cultivado no período chuvoso.

\section{MATERIAL E MÉTODOS}

O experimento foi conduzido de abril a julho de 2002, na Fazenda Santa Júlia Agro-Comercial Exportadora de Frutas Tropicais Ltda., município de Mossoró. O solo da área é um Latossolo Vermelho Eutrófico, textura média fase caatinga hiperxerófila, relevo plano. Os resultados da análise química do solo, camada entre 0 e $20 \mathrm{~cm}$ de profundidade, foram: $\mathrm{pH}$ (água 1:2,5) de 7,80; $\mathrm{Ca}=$ $3,20 \mathrm{cmol}_{\mathrm{c}} \mathrm{dm}^{-3} ; \mathrm{Mg}=1,20 \mathrm{cmol}_{\mathrm{c}} \mathrm{dm}^{-3}$; $\mathrm{K}=0,35 \mathrm{cmol}_{\mathrm{c}} \cdot \mathrm{dm}^{-3} ; \mathrm{Na}=0,06 \mathrm{cmol}_{\mathrm{c}}$ $\mathrm{dm}^{-3} ; \mathrm{P}=146 \mathrm{mg} \mathrm{dm}{ }^{-3}$. A precipitação pluviométrica $(\mathrm{mm})$, a umidade relativa $(\%)$, a temperatura média $\left({ }^{\circ} \mathrm{C}\right)$ e a evapotranspiração média $\left(\mathrm{mm} \mathrm{dia}^{-1}\right)$ durante a condução do experimento foram de $435 ; 82,6 ; 26,57$ e 3,92, respectivamente.

Utilizou-se o delineamento experimental em blocos casualizados, em esquema fatorial $5 \times 3$, com quatro repetições. Os tratamentos consistiram da combinação de cinco tipos de coberturas do solo: filmes de polietileno amarelo, marrom, preto, prateado e solo descoberto; e três lâminas de irrigação: $\mathrm{L}_{1}=100 \%(153,60 \mathrm{~m} \mathrm{~m})$, $\mathrm{L}_{2}=86 \%(131,40 \mathrm{~mm})$ $\mathrm{L}_{3}=71 \%(109,10 \mathrm{~mm})$ da lâmina padrão. A lâmina padrão correspondeu à lâmina total de irrigação estimada para o cultivo de melão sem cobertura do solo. O percentual da lâmina padrão entre as lâminas variou ao longo do ciclo, considerando as fases fenológicas em que as plantas são mais ou menos tolerantes ao déficit hídrico (DOORENBOS; KASSAM, 1994).

Cada parcela experimental foi composta de três fileiras de $6,0 \mathrm{~m}$ de comprimento, espaçadas de 2,40 $\mathrm{m}$ com duas plantas por gotejador, espaçado de 0,50 $\mathrm{m}$, o que resultou numa população de 16.667 plantas por hectare. As avalia- ções foram realizadas apenas na fileira central, desprezando as duas plantas das extremidades.

O preparo do solo constou de uma aração e duas gradagens, seguidas da confecção dos camalhões de $0,90 \mathrm{~m}$ de largura e $0,20 \mathrm{~m}$ de altura, distanciada entre eixos de 2,40 m. A adubação de pré-plantio consistiu de $2,5 \mathrm{t} \mathrm{ha}^{-1}$ do composto orgânico Polifértil ${ }^{\grave{o}}$ e, $220 \mathrm{~kg}$ ha $^{-1}$ de MAP (fosfato monoamônico), o que representou $80 \mathrm{~kg}$ de $\mathrm{N}, 170 \mathrm{~kg}$ de $\mathrm{P}_{2} \mathrm{O}_{5}$ e $70 \mathrm{~kg}$ de $\mathrm{K}_{2} \mathrm{O}$.

A irrigação foi por gotejamento com emissores de vazão $2,3 \mathrm{~L} \mathrm{~h}^{-1}$ para pressão de serviço de $100 \mathrm{kPa}$. As linhas laterais foram dispostas de forma que as mesmas pudessem atender as três fileiras de plantas de uma mesma parcela, o que permitiu o controle individual da irrigação de cada unidade experimental.

A quantidade de água necessária para irrigação (lâmina padrão) foi estimada de acordo com a evapotranspiração da cultura (ALLEN et al., 1998), que leva em consideração a evapotranspiração de referência (ETo) e o coeficiente de cultivo (Kc) da cultura para cada estádio de desenvolvimento $\mathrm{e}$ a precipitação efetiva. A evapotranspiração de referência foi calculada pelo método de PermanMonteith, proposto pela FAO (ALLEN et al., 1998), com dados da Estação Climatológica da ESAM, distante 20 $\mathrm{Km}$ do local do experimento, e os coeficientes de cultivo recomendados por Allen et al. (1998). Utilizou-se a metodologia do Kc dual, que depois de calculados e ajustados pelo monitoramento da umidade do solo por tensiometria na parcela considerada padrão, apresentou valores de 0,25; 1,00 e 0,70 , respectivamente, para os estádios fenológicos I, III e final do ciclo. A precipitação efetiva foi quantificada apenas para fins de estimativa da lâmina necessária de irrigação para o tratamento padrão. Assim, considerando que a chuva infiltrada atinge o sistema radicular em apenas $30 \%$ da superfície, percentagem de solo molhado, e que somente acima de $5 \mathrm{~mm}$ de chuva começa haver infiltração efetiva da água no solo, e que cerca de apenas $1 / 3$ desta consegue infiltrar na superfície do bulbo molhado, a precipitação efetiva (Pef) foi cal- 
culada através da equação: Pef=Máximo $\{$ Mínimo[0,1(P-5); LPI];0\} sendo $\mathrm{P}=$ precipitação total, em mm; LPI= a lâmina de água prontamente disponível no solo calculada segundo Keller e Bliesner (1990) com valores variando de 2,1 a 4,2 $\mathrm{mm}$ dependendo da profundidade efetiva do sistema radicular. Os dados de precipitação pluviométrica $(435 \mathrm{~mm})$ foram medidos na área experimental. As lâminas de irrigação pré-estabelecidas conforme a metodologia descrita, foram ajustadas ao longo do ciclo da cultura para o tratamento padrão, através do monitoramento da umidade do solo.

A lâmina total de irrigação (LTI) foi calculada diariamente para o tratamento padrão por meio da equação: LTI $=($ ETo.Kc - Pef $)$. Tr.EU ${ }^{-1}$, sendo Tr a taxa de percolação profunda não controlada, assumida 1,05 (KELLER; BLIESNER,1990), e EU o coeficiente de uniformidade de emissão, que foi de 0,96 .

A freqüência de irrigação foi determinada em função da necessidade líquida de irrigação diária e a lâmina de água prontamente disponível (LPI), proporcionando frequiência de uma a duas irrigações diárias para os dias que necessitou de irrigação.

Após a instalação do sistema de irrigação, procedeu-se a colocação dos filmes de polietileno nas parcelas dos tratamentos com cobertura, seguida da abertura dos orifícios de plantio, dois em cada gotejador distanciados $0,15 \mathrm{~m}$, com um vazador de $8 \mathrm{~mm}$ de diâmetro.

A semeadura foi direta, realizada em 29/04/2002 e paralelamente, procedeuse também a semeadura em bandejas de 128 células para produção de mudas para posterior replantio. A população de plantas foi corrigida através do transplantio das mudas, 11 dias após a semeadura direta.

As adubações de cobertura foram realizadas diariamente em fertirrigação, seguindo as recomendações da análise de solo, e obedecendo aos estádios de desenvolvimento da cultura. As quantidades totais de adubo utilizadas por hectare até o final do ciclo foram: $121 \mathrm{~L} \mathrm{de}$ ácido nítrico; 190 L de ácido fosfórico; $508 \mathrm{~kg}$ de nitrato de potássio; $2 \mathrm{~kg}$ de nitrato de amônio; $79 \mathrm{~kg}$ de nitrato de cálcio; $126 \mathrm{~kg}$ de sulfato de potássio e $30 \mathrm{~kg}$ de sulfato de magnésio, o que re-

Tabela 1. Valores de massa média dos frutos comercializáveis. Mossoró, ESAM, 2002.

\begin{tabular}{lccccc}
\hline $\begin{array}{c}\text { Lâminas de } \\
\text { irrigação } \\
(\mathbf{m m})\end{array}$ & $\begin{array}{c}\text { Polietileno } \\
\text { amarelo }\end{array}$ & $\begin{array}{c}\text { Polietileno } \\
\text { marrom }\end{array}$ & $\begin{array}{c}\text { Polietileno } \\
\text { preto }\end{array}$ & $\begin{array}{c}\text { Polietileno } \\
\text { prateado }\end{array}$ & $\begin{array}{c}\text { Solo } \\
\text { descoberto }\end{array}$ \\
\hline L1 $(153,60)$ & $1,54 \mathrm{~A} \mathrm{a}$ & $1,57 \mathrm{~A} \mathrm{a}$ & $1,64 \mathrm{~A}$ a & $1,67 \mathrm{~A} \mathrm{a}$ & $1,24 \mathrm{~B}^{*} \mathrm{~b}^{+}$ \\
$\mathrm{L} 2(131,40)$ & $1,52 \mathrm{~A} \mathrm{a}$ & $1,57 \mathrm{~A} \mathrm{a}$ & $1,56 \mathrm{~A} \mathrm{a}$ & $1,59 \mathrm{~A} \mathrm{a}$ & $1,56 \mathrm{~A} \mathrm{a}$ \\
L3 $(109,10)$ & $1,74 \mathrm{~A} \mathrm{a}$ & $1,63 \mathrm{AB}$ a & $1,57 \mathrm{AB}$ a & $1,70 \mathrm{~A} \mathrm{a}$ & $1,39 \mathrm{~B} \mathrm{ab}$ \\
\hline C. V. $(\%)$ & & & & 8,45 \\
\hline
\end{tabular}

* Letras iguais, maiúsculas nas linhas e minúsculas nas colunas, não diferem entre si a 5\% de probabilidade pelo teste de Tukey.

presentou por hectare $97,49 \mathrm{~kg}$ de $\mathrm{N}$, $100,7 \mathrm{~kg}$ de $\mathrm{P}_{2} \mathrm{O}_{5}, 286,52 \mathrm{~kg}$ de $\mathrm{K}_{2} \mathrm{O}$, 26,86 kg de Ca e 4,8 kg de $\mathrm{MgO}$.

Para o controle fitossanitário foram feitas pulverizações, de acordo com as recomendações técnicas adotadas pela Fazenda Santa Júlia. Foram realizadas quatro capinas manuais com enxada nas parcelas sem cobertura e entre canteiros das parcelas com cobertura. As ervas daninhas que surgiram próximas às covas foram eliminadas manualmente.

Foram realizadas duas colheitas, sendo a primeira aos 66 dias após a semeadura e a segunda, seis dias após a primeira. O ponto de colheita adotado foi a coloração dos frutos, ou seja, quando os mesmos apresentavam-se amarelos.

A classificação foi realizada por tamanho, ou seja, pelo agrupamento dos frutos em tipo, de acordo com o número de frutos por caixa (4 a 12), com capacidade de 10 e $13 \mathrm{~kg}$ para mercado externo e interno, respectivamente. Os frutos com bactéria, brocados, deformados, queimados pelo sol e com viroses foram considerados refugos Foram avaliados: massa média de frutos comercializáveis (PMFC), número de frutos comercializáveis (NFC), número de frutos refugos (NFR), número total de frutos (NTF), rendimento de frutos comercializáveis (RFC), rendimento de frutos refugos (RFR) e rendimento de frutos total (RFT).

Na primeira colheita foram tomados quatro frutos por parcela para determinação da firmeza da polpa através da resistência à penetração usando penetrômetro com "plunger" de $8 \mathrm{~mm}$ de diâmetro; teor de sólidos solúveis totais (SST) usando refratômetro digital com compensação automática de temperatura e espessura de polpa com uma régua graduada.

As análises de variância das características foram realizadas através do aplicativo software SPSSPC (NORUSSIS, 1990).

\section{RESULTADOS E DISCUSSÃO}

Observou-se interação significativa entre os fatores tipos de coberturas do solo e lâminas de irrigação apenas para massa média de frutos comercializáveis.

Verificou-se que na lâmina L1 (153,6 mm) as coberturas de solo com filmes de polietileno resultaram em maior massa média de frutos comercializáveis, quando comparadas com o solo descoberto. Comportamento semelhante observou-se na lâmina L3 (109,10 mm), embora estatisticamente o solo descoberto não tenha diferido das coberturas com filmes de polietileno marrom e preto (Tabela 1). Por outro lado, na lâmina L2 (131,40 mm) não se constatou diferença entre os tipos de coberturas do solo para esta característica (Tabela 1). As coberturas do solo com filmes de polietileno registraram massa média de frutos comercializáveis semelhantes, independentemente da lâmina de irrigação aplicada, enquanto que o solo descoberto apresentou maior valor dentro da lâmina L2 (131,4 mm). É provável que as melhores condições de umidade e de sanidade das plantas, proporcionadas pelos efeitos das coberturas plásticas, tenham influenciado estes resultados, quando comparadas com o solo descoberto. A massa média de fruto é uma característica inerente à cultivar, entretanto pode sofrer influência dos tratos culturais, principalmente da sanidade da cultura. A redução da área foliar implica em redução da capacidade 
M. Z. Negreiros et al.

Tabela 2. Valores médios para o número de frutos comercializáveis (NFC), número de frutos refugos (NFR), número total de frutos (NTF), rendimento de frutos comercializáveis (RFC), rendimento de frutos refugos (RFR) e rendimento total de frutos (RTF). Mossoró, ESAM, 2002.

\begin{tabular}{lccccccc}
\hline $\begin{array}{l}\text { Tipos de } \\
\text { cobertura }\end{array}$ & NFC (frutos/ha) & NFR (frutos/ha) & NTF (frutos/ha) & RFC (t/ha) & RFR (t/ha) & RTF (t/ha) \\
\hline P. amarelo & $7.778 \mathrm{a}$ & $8.150 \mathrm{a}$ & $15903 \mathrm{a}$ & $12,52 \mathrm{a}$ & $11,49 \mathrm{a}$ & $24,02 \mathrm{a}$ \\
P. marrom & $7.986 \mathrm{a}$ & $8.125 \mathrm{a}$ & $16111 \mathrm{a}$ & $12,59 \mathrm{a}$ & $11,50 \mathrm{a}$ & $24,29 \mathrm{a}$ \\
P. preto & $7.361 \mathrm{a}$ & $8.125 \mathrm{a}$ & $15436 \mathrm{a}$ & $11,81 \mathrm{a}$ & $11,32 \mathrm{a}$ & $23,13 \mathrm{a}$ \\
P. prateado & $9.306 \mathrm{a}$ & $6.597 \mathrm{a}$ & $15903 \mathrm{a}$ & $15,21 \mathrm{a}$ & $9,16 \mathrm{a}$ & $24,37 \mathrm{a}$ \\
Solo descoberto & $4.924 \mathrm{~b}$ & $7.424 \mathrm{a}$ & $12348 \mathrm{~b}$ & $6,93 \mathrm{~b}$ & $8,87 \mathrm{a}$ & 15,81 & $\mathrm{~b}$ \\
Lâminas de irrigação $(\mathbf{m m})$ & $7.588 \mathrm{a}$ & $7.237 \mathrm{a}$ & $14.825 \mathrm{a}$ & $11,95 \mathrm{a}$ & $10,00 \mathrm{a}$ & $21,96 \mathrm{a}$ \\
L1 (153,60) & $7.417 \mathrm{a}$ & $8.208 \mathrm{a}$ & $15.625 \mathrm{a}$ & $11,64 \mathrm{a}$ & $11,45 \mathrm{a}$ & $23,08 \mathrm{a}$ \\
L2 (131,40) & $7.451 \mathrm{a}$ & $7.598 \mathrm{a}$ & $15.125 \mathrm{a}$ & $12,22 \mathrm{a}$ & $10,02 \mathrm{a}$ & $22,24 \mathrm{a}$ \\
\hline L3 (109,10) & 31,44 & 23,43 & 17,15 & 32,74 & 27,45 & 20,53 \\
\hline C.V.(\%). & & & & & &
\end{tabular}

${ }^{1}$ Médias seguidas da mesma letra não diferem entre si a 5\% de probabilidade pelo teste de Tukey;

fotossintética da planta e, conseqüentemente, menor quantidade de carboidratos para os frutos (TAIZ; ZEIGER, 1998).

Em condições de solos semelhantes, Câmara (2004) e Saldanha (2004) testando os mesmos tratamentos em híbridos de melão 'Goldex' (amarelo) e 'Torreon' (cantaloupe), respectivamente, no período chuvoso e de verão, não observaram interação significativa entre os fatores estudados para esta característica. Os autores verificaram que as massas médias de frutos comercializáveis aumentaram em função das lâminas de irrigação aplicadas. No período chuvoso, Câmara (2004) constatou que não houve efeito significativo dos tipos de coberturas do solo sobre a massa média de frutos comercializáveis, porém no verão Saldanha, (2004) verificou que o filme plástico amarelo registrou maior massa média de frutos comercializáveis em relação ao preto e o prateado. Essa diferença pode ser atribuída à natureza genética inerente a cada híbrido, conferindo comportamento distinto de acordo com o maior ou menor grau de adaptação dos materiais ao ambiente em que são cultivados.

Considerando o número e rendimento de frutos comercializáveis e totais, verificou-se que as coberturas do solo com filmes plásticos registraram valores superiores ao solo descoberto (Tabela 2). Para o número e produtividade de frutos comercializáveis houve um aumento percentual médio de $64,66 \%$ (3.184 frutos ha-1) e 88,78\% (6,15 tha $\left.{ }^{-1}\right)$, respectivamente, em relação ao solo descoberto. Para o número e produtividade de frutos totais, este acréscimo foi de $28,27 \%$ (3.490 frutos $\cdot$ ha $\left.^{-1}\right)$ e $51,5 \%$ $\left(8,14 \mathrm{t} \cdot \mathrm{ha}^{-1}\right)$, respectivamente. Incrementos de 70 e $72 \%$, 25 e $33 \%$, no número e produtividade de frutos comercializáveis também foram constatados por Câmara (2004) e Almeida Neto (2004), trabalhando com coberturas de solo semelhantes e híbridos diferentes (Goldex-amarelo e Torreon-cantaloupe), respectivamente, no período chuvoso e seco. É provável que o maior desenvolvimento vegetativo do meloeiro (PÔRTO et al., 2003), traduzido pelos efeitos benéficos das coberturas plásticas, tenha contribuído para elevar as atividades fotossintéticas das plantas, resultando em maior número e produtividade de frutos nestes tratamentos, quando comparados com o solo descoberto.

Entretanto, Araújo et al. (2000) e Ferreira et al. (2001) nas condições de Carnaubais (RN), não observaram diferenças significativas entre os filmes plásticos (preto e prateado) e o tratamento solo descoberto. Os autores atribuíram este fato à elevada intensidade luminosa da região no período dos experimentos (setembro a janeiro), o que contribuiu para uma intensa atividade fotossintética das plantas, ocorrendo assim compensação do número de frutos por hectare.

Os tipos de coberturas de solo não influenciaram de forma significativa $o$ número e rendimento de frutos refugos (Tabela 2). Câmara (2004) trabalhando com melão amarelo 'Goldex ' cultivado no período chuvoso e com coberturas de solo semelhantes também não observou influência dos tratamentos sobre estas características.

Constataram-se, neste experimento, elevado número de frutos refugos, aproximadamente, $50 \%$ do total produzido sob os diferentes tipos de coberturas de solo (Tabela 2). Câmara (2004) também verificou elevado número de frutos refugos de melão 'Goldex ' cultivado no período chuvoso. É provável que as condições edafoclimáticas, principalmente temperatura, umidade relativa do ar e do solo, propiciadas pelas chuvas ocorridas no período da condução do experimento $(435 \mathrm{~mm})$ tenham influenciado estes resultados, uma vez que se observou significativa incidência de doenças bacterianas, fúngicas e viróticas, afetando a fisiologia da planta e favorecendo a formação de frutos.

As lâminas de irrigação não influenciaram de modo significativo o número e rendimento de frutos comercializáveis, refugos e total (Tabela 2). Provavelmente as precipitações ocorridas durante a condução do experimento tenham influenciado nestes resultados (435 mm), compensando as menores lâminas de irrigação aplicadas $(\mathrm{L} 2=131,40 \mathrm{~mm} \quad \mathrm{e}$ L3=109,10 mm). Embora se tenha aplicado lâminas de irrigação diferenciadas durante o ciclo da cultura a baixa Eto verificada durante o período de cultivo e um número significativo de dias com chuvas efetivas próxima a $\mathrm{ET}_{\mathrm{C}}$, anulou o efeito dos dias anteriores que as plantas foram submetidas a déficit hídrico $\left(\mathrm{L}_{2}\right.$ e $\left.\mathrm{L}_{3}\right)$. 
Entretanto outros autores (COSTA et al., 2002; ALMEIDA NETO, 2004; SALDANHA, 2004; ANDRADE, et al., 2004) observaram incrementos no rendimento de frutos comercializáveis de melão Cantaloupe 'Torreon' cultivado no período de verão à medida que aumentaram as lâminas de irrigação. $\mathrm{O}$ melhor desempenho do meloeiro nas maiores lâminas de irrigação nesse período provavelmente possibilitou um adequado balanço de água no solo que permitiu melhor disponibilidade de água e de nutrientes para a cultura.

Os rendimentos médios de frutos comercializáveis e totais alcançados no presente trabalho variaram de 6,93 a 15,20 t ha ${ }^{-1}$ e de 15,81 a 24,37 $\mathrm{t} \mathrm{ha}^{-1}$, respectivamente, abaixo dos obtidos em experimentos com "mulch" na região, porém em período seco (ARAÚJO et al., 2000; FERREIRA et al., 2001; SILVA, 2002). Entretanto, deve-se considerar que o experimento foi desenvolvido no período chuvoso quando se registrou $435 \mathrm{~mm}$ de chuvas durante o ciclo da cultura. Portanto, o rendimento obtido neste trabalho foi aceitável, considerando que as atividades dos produtores são praticamente suspensas nesta época, fazendo com que o preço do melão seja mais elevado.

Os frutos foram classificados em tipo exportação e mercado interno. Aqueles que não se enquadraram na classificação padronizada pela empresa para encaixamento foram considerados refugos. Considerando o melão tipo exportação, verificou-se que os maiores percentuais de frutos se concentraram nos tipos 5; 6 e 7, com as coberturas de filmes de polietileno registrando os maiores valores em relação ao solo descoberto. A alta umidade relativa do ar e do solo, durante o período chuvoso, provavelmente, contribuiu para redução no percentual de frutos tipo exportação no solo descoberto, em virtude do aumento da mancha de encosto e sanidade dos frutos. Entretanto para o mercado interno observou-se que os maiores percentuais de frutos foram registrados nos tipos 7; 8 e 9, com o solo descoberto apresentando maiores valores nesta categoria. De modo geral, observou-se maior percentagem de frutos classificados para mercado interno, principalmen-

Tabela 3. Valores médios para firmeza de polpa, espessura de polpa e teor de sólidos solúveis totais. Mossoró, ESAM, 2002.

\begin{tabular}{lccc}
\hline $\begin{array}{l}\text { Tipos de cobertura } \\
\text { do solo }\end{array}$ & $\begin{array}{c}\text { Firmeza da polpa } \\
(\mathbf{N})\end{array}$ & $\begin{array}{c}\text { Espessura da polpa } \\
(\mathbf{c m})\end{array}$ & $\begin{array}{c}\text { Sólidos solúveis } \\
(\%)\end{array}$ \\
\hline Polietileno amarelo & $32,31 \mathrm{~b}^{1}$ & $2,91 \mathrm{ab}$ & $8,37 \mathrm{a}$ \\
Polietileno marrom & $34,24 \mathrm{ab}$ & $2,92 \mathrm{a}$ & $8,58 \mathrm{a}$ \\
Polietileno preto & $33,88 \mathrm{ab}$ & $3,00 \mathrm{a}$ & $8,32 \mathrm{a}$ \\
Polietileno prateado & $34,36 \mathrm{ab}$ & $2,98 \mathrm{a}$ & $8,40 \mathrm{a}$ \\
Solo descoberto & $36,27 \mathrm{a}$ & $2,70 \mathrm{~b}$ & $7,04 \mathrm{~b}$ \\
Lâminas de irrigação (mm) & $33,78 \mathrm{a}$ & $2,89 \mathrm{a}$ & $8,16 \mathrm{a}$ \\
L1 $(153,60)$ & $34,12 \mathrm{a}$ & $2,88 \mathrm{a}$ & $8,19 \mathrm{a}$ \\
L2 $(131,40)$ & $34,60 \mathrm{a}$ & $2,94 \mathrm{a}$ & $8,12 \mathrm{a}$ \\
\hline L3 $(109,10)$ & 6,00 & 6,21 & 12,66 \\
\hline C. V. $(\%)$ & \multicolumn{4}{l}{} \\
${ }^{1}$ Médias seguidas da mesma letra não diferem entre si a 5\% de probabilidade pelo teste de \\
Tukey;
\end{tabular}

te, aqueles provenientes do solo descoberto, demonstrando que a época de plantio influenciou na qualidade comercial dos frutos produzidos.

Em relação ao rendimento total, observou-se que, em média, 22,71 e $28,12 \%$ dos frutos produzidos sob cobertura plástica foram classificados como tipo exportação e mercado interno, respectivamente. $\mathrm{O}$ solo descoberto produziu o percentual de $4,2 \%$ de frutos tipo exportação, 32\% tipo mercado interno e 51,92\% de frutos refugos.

Não houve interação significativa entre os tipos de coberturas de solo e lâminas de irrigação para firmeza de polpa, espessura de polpa e o teor de sólidos solúveis.

Considerando os fatores isolados verificou-se que a firmeza da polpa, espessura de polpa e o teor de sólidos solúveis foram afetados de forma significativa pelos tipos de coberturas do solo (Tabela 3). Para a firmeza de polpa o filme de polietileno amarelo e o solo descoberto apresentaram, em média, o menor $(32,31 \mathrm{~N})$ e o maior $(36,27 \mathrm{~N})$ valor, respectivamente (Tabela 3). Câmara (2004) trabalhando com melão amarelo 'Goldex' no período chuvoso e utilizando coberturas plásticas semelhantes verificou que estes tratamentos proporcionaram menor firmeza de frutos quando comparados com o solo descoberto. As coberturas plásticas, por proporcionarem maior retenção de água e reduzir a evaporação da superfície do solo, não permitiram que a umidade diminuísse o suficiente no período da co- lheita com a diminuição das lâminas de irrigação, mantendo uma menor firmeza dos frutos. Segundo Costa (1999), quanto mais água se aplica para uma cultura, até um certo limite, esta deve produzir frutos que apresentam menor resistência à penetração e conseqüentemente, menores valores de firmeza.

Para a espessura de polpa verificouse que as coberturas do solo com filmes de polietileno apresentaram maiores valores em relação ao solo descoberto, com exceção do filme amarelo (Tabela 3). Trabalhando com melão 'Goldex ' no período chuvoso e com coberturas plásticas semelhantes Câmara (2004) registrou também menor espessura de polpa para o tratamento solo descoberto $(2,86$ $\mathrm{cm})$. É possível que a redução da área foliar nas parcelas sem cobertura plástica tenha proporcionado frutos de menor tamanho, menor massa média e menor espessura de polpa. A redução da área foliar implica em redução da capacidade fotossintética da planta e, conseqüentemente, menor quantidade de carboidratos para os frutos (TAIZ; ZEIGER, 1998).

Considerando os teores de sólidos solúveis verificou-se que os filmes de polietileno registraram um acréscimo médio de 19,6\% em relação ao solo descoberto (Tabela 3). Esses resultados corroboram com os observados por outros pesquisadores (BRANDEMBERG; WIELDENFELD, 1997; MARTINS et al.,1998; CÂMARA, 2004), que verificaram aumentos nos teores de sólidos solúveis em frutos de melão com o 
emprego da cobertura plástica. Entretanto, não estão de acordo com os obtidos por Araújo et al. (2000) e Ferreira et al. (2001), os quais não observaram influência da cobertura do solo sobre os teores de sólidos solúveis em melão amarelo 'Gold Mine' cultivado, respectivamente, no período setembro a novembro e novembro a janeiro. Como o presente trabalho foi desenvolvido no período chuvoso, é possível que a cobertura do solo com filmes de polietileno tenha atuado como meio de regular a quantidade de água resultante do excesso de chuvas, contribuindo para a maior uniformidade nos teores de sólidos solúveis nos frutos de melão. Segundo Pedrosa (1997), o clima exerce influência na qualidade do melão, principalmente temperatura, luminosidade e umidade do solo e do ar. Mota et al. (2001), observaram que frutos de melão 'Gold Mine' produzidos na época chuvosa permaneceram com os teores de sólidos solúveis na faixa dos $8,0 \%$.

As lâminas de irrigação não afetaram de modo significativo a firmeza de polpa, espessura de polpa e o teor de sólidos solúveis (Tabela 3). Com relação ao teor de sólidos solúveis, outros pesquisadores (COSTA, 1999; BEZERRA; MOURÃO, 2000) obtiveram resultados semelhantes trabalhando com diferentes níveis de irrigação. No entanto, Medeiros et al. (2000), observaram que o excesso de água aplicado na fase de crescimento dos frutos promoveu redução no teor de sólidos solúveis.

O teor de sólidos solúveis deveria ser maior nos frutos das plantas submetidas às menores lâminas de irrigação, devido ao aumento da concentração de açúcares nos tecidos dos frutos (ANDRADE JÚNIOR et al., 2001; FABEIRO et al., 2002). No entanto, para esta característica não se observou tal comportamento neste trabalho (Tabela 3), provavelmente, devido à impossibilidade de reduzir o volume de água próximo à colheita, em virtude das chuvas ocorridas no período.

Em função dos resultados obtidos, conclui-se que o plantio de melão amarelo sob condições de coberturas plásticas foi viável no período chuvoso resultando em maiores produções e qua- lidade dos frutos, e que as lâminas de irrigação não afetaram significativamente a produção e qualidade dos frutos, de modo que a menor lâmina $(109,1 \mathrm{~mm})$ foi suficiente para o desenvolvimento do meloeiro.

\section{AGRADECIMENTOS}

Os autores agradecem ao CNPq pelo financiamento desta pesquisa e à Fazenda Santa Júlia Agro Comercial Exportadora de Frutos Tropicais Ltda., Mossoró, pelo apoio na instalação e condução do experimento.

\section{LITERATURA CITADA}

ALLEN, R.G., PEREIRA, L.S., RAES, D., SMITH, M. Crop evapotranspiration: guidelines for computing crop water requirements. Rome: FAO, 1998, 279 p. (FAO, Irrigation and Drainage Paper, 56).

ANDRADE JÚNIOR, A.S.; FRIZZONE, J.A.; BASTOS, E.A; CARDOSO, M.J.; RODRIGUES, B.H.N. Estratégias ótimas de irrigação para a cultura da melancia. Horticultura Brasileira, Brasília, v.36, n.2, p.301-305, 2001.

ALMEIDA NETO, A.J.; MEDEIROS, J.F.; NEGREIROS, M.Z.; LEITÃO, M.M.V.B.R.; MENEZES, J.B.; SENHOR, R.F.; GONDIM, A.R.O. Qualidade de melão Cantaloupe influenciada pelos tipos de cobertura do solo e lâminas de irrigação em solo de textura média. Horticultura Brasileira, Brasília, v.21, n.2, jul. 2003. Suplemento 2. CD-ROM. Trabalho apresentado no $43^{\circ}$ Congresso Brasileiro de Olericultura, 2003.

ALMEIDA NETO, A.J. Produção e qualidade de melão cantaloupe influenciadas por coberturas do solo e lâminas de irrigação em solo argiloso. 2004.74 f. (Tese mestrado) -Escola Superior de Agricultura de Mossoró, Mossoró.

ALVES, R.E. (org). MELÃO: Pós-colheita. EMBRAPA, Embrapa Agroindústria Tropical/ MAA, Brasília: Embrapa Comunicação para Transferância de Tecnologia, 2000. 43p.il.

ANDRADE, P.C.S.G.; NEGREIROS, M.Z.; MEDEIROS, J.F.; LIMA JÚNIOR, O.J.; SANTOS, S.C.L.; BEZERRA NETO, F. LISBOA, R.K.C.; BARROS JÚNIOR, A.P. Produção de melão cantaloupe com diferentes tipos de cobertura do solo e lâminas de irrigação. Horticultura Brasileira, Brasília, v.22, n.2, jul. 2004. Suplemento 2. CD-ROM. Trabalho apresentado no $44^{\circ}$ Congresso Brasileiro de Olericultura, 2004.

ARAÚJO, A.P.; NEGREIROS, M.Z;; BEZERRA NETO, F.; PEDROSA, J.F.; FERREIRA, R.L.F. Cobertura do solo e métodos de plantio na qualidade de melão. Horticultura Brasileira, Brasília, v.18, p.515-516, Jul., 2000. Suplemento 1. Trabalho apresentado no $40^{\circ}$ Congresso Brasileiro de Olericultura, 2000.

BAKER, J.T.; EARHART, D.R.; BAKER, M.L.; DAINELLO, F.J.; HABY, V.A. Interactions of poultry litter, polyethylene mulch, and floating row covers on triploid watermelon. HortScience, v.33, n.5, p.810-813, 1998.
BRANDENBERGER, L.; WIENDENFELD, B. Physical characteristics of mulches and their impact on crop response and profitability in muskmelon production. Hort Technology, Alexandria, v.7, n.2, p.165-169, 1997.

CÂMARA, M.J.T. Produção e qualidade de melão amarelo influenciado por coberturas do solo e lâminas de irrigação no período chuvoso. 2004. 80 f. (Tese mestrado) - Escola Superior de Agricultura de Mossoró, Mossoró.

COSTA, M.C. Efeito de diferentes lâminas de água com dois níveis de salinidade na cultura do meloeiro. 1999.115 f. (Tese doutorado) - Universidade Estadual Paulista Júlio de Mesquita Filho, Botucatu. COSTA, F.A. ; NEGREIROS, M.Z.; MEDEIROS, J.F.; BEZERRA NETO, F.; PÔRTO, D.R.Q.; CHAVES, S.W.P. Rendimento de melão Cantaloupe em diferentes coberturas do solo e lâminas de irrigação. Horticultura Brasileira, Brasília, v.20, n.2, jul. 2002. Suplemento 2. CDROM. Trabalho apresentado no $42^{\circ}$ Congresso Brasileiro de Olericultura, 2002.

COSTA, N.D. ; DIAS, R.C.S. ; FARIA, C.M.B.; TAVARES, S.C.H. ;TERAO, D. Cultivo do melão Embrapa Semi-Árido, Circular Técnica, Petrolina-PE, n.59, p.37-39. 2000.

DOORENBOS, J.; KASSAM, A.H. Efeito da água no rendimento das culturas. Traduzido por: H.R. Gheyi, A.A. Sousa, F.A.V. Damasceno e J.F. de Medeiros. Campina Grande: UFPB, 1994. 306 p. (FAO. Estudos de Irrigação e Drenagem, 33). FABEIRO, C. SANTA OLALLA, F.M.; JUAN, J.A. Production of muskmelon (Cucumis melo L) under controlled deficit irrigation in a semi-arid climate. Agricultural Water Management, Amsterdam, v.54, p.93-105, 2002.

FERREIRA, R.L.F.; NEGREIROS, M.Z.; LEITÃO, M.M.V.B.R.; ;PEDROSA, J.F.; BEZERRA NETO, F.; ESPÍNOLA SOBRINHO, J.; COELHO, J.K.S.; LIRA, G.S. Rendimento de melão 'Gold Mine' em diferentes coberturas de solo e métodos de plantio. Horticultura Brasileira, Brasília, v.19, jul, 2001.Suplemento 2. CD ROM. Trabalho apresentado no $41^{\circ}$ Congresso Brasileiro de Olericultura, 2001.

HAM, J.M.; KLUITENBERG, G.J.; LAMONT, W.J. Optical properties of plastic mulches effect the field temperature regime. Journal of the American Society for Horticulture Science, Alexandria, v.118, n.2, p.188-193. 1993.

KELLER, J.; BLIESNER, R.D. Sprinkler and trickle irrigation. New York: Van Nostrand Reinhold, 1990. 652 p.

MARTINS, S.R.; PEIL, R.M.; SCHWENGBER, J.E.; ASSIS, F.N.; MENDES, M.E.G. Produção de melão em função de diferentes sistemas de condução de plantas em ambiente protegido. Horticultura Brasileira, Brasília, v.16, n.1, p.24-30, 1998.

MEDEIROS, J.F.; SIMÕES, A.N.; ALVES, L.P.; COSTA, M.C.; SCALOPPI, E.J.; MENEZES, J.B. Qualidade de melão amarelo cultivar 'Gold Mine' submetido a diferentes lâminas de irrigação e dois níveis de salinidade. Horticultura Brasileira, Brasília, v.18, Suplemento 1. Julho, p.614-615. 2000. Trabalho apresentado no $40^{\circ}$ Congresso Brasileiro de Olericultura, 2000.

MOTA, J.K.M.; MENEZES, J.B.; MORAIS, E.A.; GÓIS, V.A.; SOUZA, P.A.; COSTA, F.B. Qualidade pós-colheita de melão 'Gold Mine'produzido na época das chuvas. Horticultura Brasileira, Brasília, v.19, n.2, jul.2001. Suplemento, CD-ROM. Trabalho apresentado no $41^{\circ}$ Congresso Brasileiro de Olericultura, 2001. 
NORUSIS, M.J. SPSS Statistics. Illinois: SPSS Inc., 1984.

PEDROSA, J.F. Cultura do melão. Mossoró-RN, ESAM, 1997. 51 f. (apostila)

PÔRTO, D.R.Q.; GONDIM, A.R.O.; MEDEIROS, J.F.; NEGREIROS, M.Z.; BEZERRA NETO, F.; LEITÃO, M.M.V.B.R.; ANDRADE, P.C.S.G.; ALMEIDA NETO, J. Crescimento de melão Cantaloupe 'Torreon" em diferentes coberturas de solo e lâminas de irrigação nas condições de Mossoró-RN. Horticultura Brasileira, Brasília, v.21, n.2, jul. 2003. Suplemento 2. CD-ROM. Trabalho apresentado no $43^{\circ}$ Congresso Brasileiro de Olericultura, 2003.

SALDANHA, T.R.F.C.; MEDEIROS, J.F.; NEGREIROS, M.Z.; MENEZES, J.B.; BEZERRA NETO, F.; ANDRADE, J.C.;COSTA, F.B.; GONDIM, A.R.O. Qualidade de melão cantaloupe "Torreon "cultivado em solo arenoso com diferentes coberturas e lâminas de irrigação e armazenado sob refrigeração. Horticultura Brasileira Brasília, v.21, n.2, jul. 2003. Suplemento 2. CDROM. Trabalho apresentado no $43^{\circ}$ Congresso Brasileiro de Olericultura, 2003.
SALDANHA, T.R.F.C. Produção e qualidade de melão cantaloupe cultivado sob condições de diferentes tipos de cobertura e lâminas de irrigação. 2004. 105 f. (Tese mestrado) - Escola Superior de Agricultura de Mossoró, Mossoró.

SAMPAIO, R.A.; ARAÚJO, W.F. Importância da cobertura plástica do solo sobre o cultivo de hortaliças. Agropecuária Técnica, v.22, n.1/2, p. 112, 2001.

SGANZERLA, E. Nova Agricultura: A fascinante arte de cultivar com os plásticos. 4. ed. Porto Alegre: Plasticultura Gaúcha, 1991. 303 p.

SILVA, M.C.C. Crescimento, produtividade e qualidade de frutos do meloeiro sob diferentes níveis de salinidade da água de irrigação e cobertura do solo. 2002. 65 f. (Tese mestrado) - Escola Superior de Agricultura de Mossoró, Mossoró.
STRECK, N.A.; HELDWEIN, A.B.; BURIOL, G.A.; SCHNEIDER, F.M.; NARDI, C. Effect of colored plastic mulches on soil and air temperature inside a plastic greenhouse. Revista Brasileira de Agrometeorologia, Santa Maria, v.5, n.2, p.165170, 1997.

TAIZ, L.; ZEIGER, E. Plant Physiology, 2.ed. Sunderland: Sinauer Associates, Inc., Publishers, 1998. $792 \mathrm{p}$. 